\title{
Subcortical Volumetric Reductions in Adult Niemann-Pick Disease Type C: A Cross-Sectional Study
}

\author{
M. Walterfang, B. Patenaude, L.A. Abel, H. Kluenemann, E.A. Bowman, M.C. Fahey, P. Desmond, W. Kelso, and D. Velakoulis
}

\begin{abstract}
BACKGROUND AND PURPOSE: Voxel-based analysis has suggested that deep gray matter rather than cortical regions is initially affected in adult Niemann-Pick type C. We sought to examine a range of deep gray matter structures in adults with NPC and relate these to clinical variables.
\end{abstract}

MATERIALS AND METHODS: Ten adult patients with NPC (18-49 years of age) were compared with 27 age- and sex-matched controls, and subcortical structures were automatically segmented from normalized T1-weighted MR images. Absolute volumes (in cubic millimeters) were generated for a range of deep gray matter structures and were compared between groups and correlated with illness variables.

RESULTS: Most structures were smaller in patients with NPC compared with controls. The thalamus, hippocampus, and striatum showed the greatest and most significant reductions, and left hippocampal volume correlated with symptom score and cognition. Vertex analysis of the thalamus, hippocampus, and caudate implicated regions involved in memory, executive function, and motor control.

CONCLUSIONS: Thalamic and hippocampal reductions may underpin the memory and executive deficits seen in adult NPC. Volume losses in other subcortical regions may also be involved in the characteristic range of motor, psychiatric, and cognitive deficits seen in the disease.

ABBREVIATIONS: ICV = intracranial volume; NFT = neurofibrillary tangle; NPC = Niemann-Pick disease type C; NUCOG = Neuropsychiatry Unit Cognitive Assessment Tool; VBM = voxel-based morphometry

$\mathrm{N}$ iemann-Pick disease type C (Online Mendelian Inheritance in Man 257220 and 607625; http://www.ncbi.nlm.nih.gov/ omim) is a progressive neurogenetic disorder, resulting from mutations to the genes encoding for the NPC1/NPC2 proteins. Impaired function of NPC1/NPC2 results in altered intracellular sterol trafficking and accumulation of gangliosides and other glycosphingolipids. ${ }^{1}$ While most patients present with neurovisceral signs in childhood, in $20 \%$ of cases, the illness presents in adults. ${ }^{1}$

Received June 9, 2012; accepted after revision August 8.

From the Melbourne Neuropsychiatry Centre (M.W., E.A.B., D.V.) and Departments of Optometry and Vision Sciences (E.A.B., L.A.A.) and Radiology (P.D.), University of Melbourne, Melbourne, Australia; Neuropsychiatry Unit (M.W., D.V.) and Department of Radiology (P.D.) and Neuropsychiatry Unit (W.K.), Royal Melbourne Hospital, Melbourne, Australia; Department of Psychiatry and Behavioral Sciences (B.P.), Stanford University, Stanford, California; Department of Psychiatry (H.K.), School of Medicine, Regensburg Universität, Regensburg, Germany; and Department of Pediatrics (M.C.F.), Monash University, Melbourne, Australia.

Please address correspondence to Mark Walterfang, MD, Neuropsychiatry Unit, Level 2, John Cade Bldg, Royal Melbourne Hospital, Melbourne 3050, Australia;

e-mail: mark.walterfang@mh.org.au

http://dx.doi.org/10.3174/ajnr.A3356
Adults demonstrate a range of central nervous system symptoms, including ataxia, dystonia, vertical supranuclear ophthalmoplegia, cognitive impairment, and psychotic illness. ${ }^{2,3}$ Because of the rarity of adult patients, few studies have examined brain changes in the disease at a group level and their relationship with clinical variables. $^{4,5}$

We previously used VBM to demonstrate that gray matter changes in NPC were most significant in basal and subcortical regions, with reductions in volume in the hippocampus, thalamus, cerebellum, and striatum. ${ }^{5}$ These findings matched both animal and human models of NPC, where these regions show the greatest ganglioside accumulation, ${ }^{6}$ and where humans develop NFTs. ${ }^{7}$ Given that the most significant reductions were in medial and subcortical gray matter regions, we aimed to both validate and extend on our previous findings by using a subcortical segmentation approach. This provided regional volumetric data for a range of subcortical structures, which were then correlated with illness variables. We subsequently used vertex analysis to examine localized changes in brain structures that showed significant volumetric change. 
Table 1: Clinical, biochemical, and ocular-motor variables for the NPC patient group

\begin{tabular}{|c|c|c|c|c|c|c|c|c|}
\hline \multicolumn{3}{|c|}{ Demographic Variables } & \multicolumn{3}{|c|}{ Illness Variables } & \multicolumn{2}{|c|}{ Biochemical Variables } & \multirow{2}{*}{$\begin{array}{c}\text { Cognitive Variables } \\
\text { NUCOG Score } \\
(/ 100)\end{array}$} \\
\hline Patient & $\begin{array}{l}\text { Age } \\
\text { (yr) }\end{array}$ & Sex & $\begin{array}{c}\text { AOO } \\
\text { (yr) }\end{array}$ & $\begin{array}{c}\text { DON } \\
\text { (yr) }\end{array}$ & $\begin{array}{c}\text { Illness } \\
\text { Scale }\end{array}$ & $\begin{array}{c}\text { Filipin } \\
\%\end{array}$ & $\begin{array}{l}\text { Cholesterol } \\
\text { Esterification } \\
\text { (pmol/h/mg) }\end{array}$ & \\
\hline 1 & 49 & $M$ & 47 & 2 & 5 & 20 & NA & 93.5 \\
\hline 2 & 23 & $M$ & 17 & 6 & 13 & 75 & 2.2 & NA \\
\hline 3 & 33 & $\mathrm{~F}$ & 29 & 4 & 9 & 25 & 1.5 & 49 \\
\hline 4 & 32 & $\mathrm{~F}$ & 26 & 6 & 7 & 60 & 5.3 & 82.5 \\
\hline 5 & 43 & $\mathrm{~F}$ & 41 & 2 & 6 & 15 & 2.3 & 89 \\
\hline 6 & 20 & $M$ & 19 & 1 & 5 & 90 & 2 & 79 \\
\hline 7 & 32 & M & 25 & 7 & 11 & 70 & 2.9 & 49 \\
\hline 8 & 31 & M & 19 & 12 & 15 & 95 & 0.3 & 51 \\
\hline 9 & 18 & M & 14 & 4 & 7 & 70 & 1.4 & 79 \\
\hline 10 & 34 & $\mathrm{~F}$ & 31 & 2 & 5 & NA & NA & 94 \\
\hline
\end{tabular}

Note:-AOO indicates age at onset of neurologic symptoms; DON, duration of neurologic symptoms; NA, not applicable; Filipin, a complex of polyene antibiotics obtained from Streptomyces filipinensis.

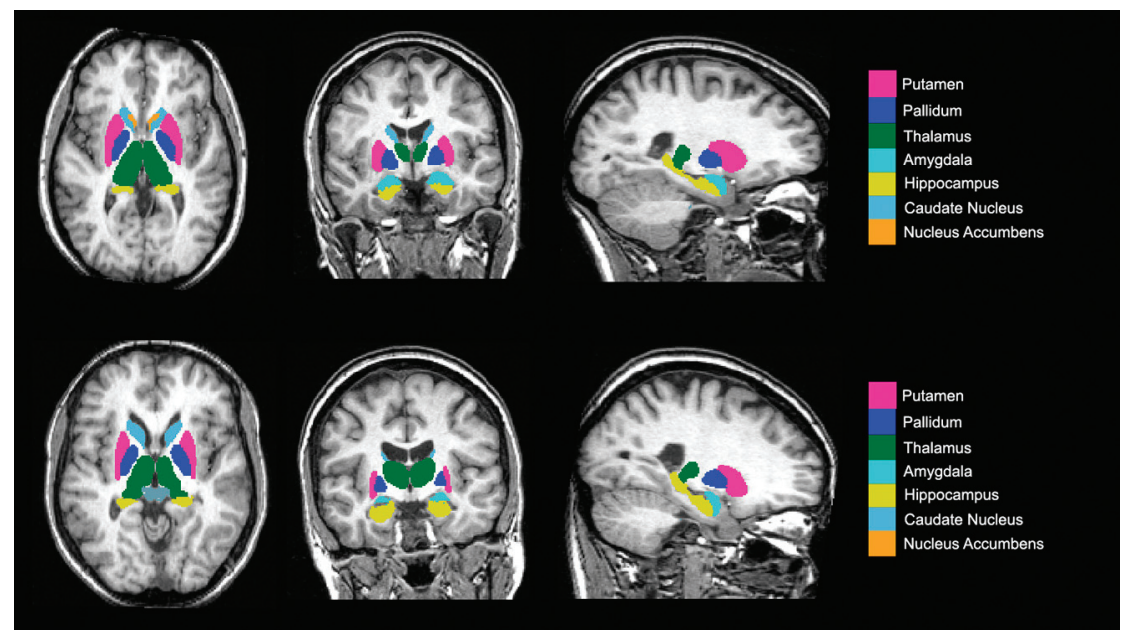

FIG 1. Axial, coronal, and sagittal sections of a T1-weighted MR image, indicating the deep gray matter regions segmented for later analysis. Top, healthy control; bottom, NPC patient.

MR Imaging Acquisition and Analysis Participants were scanned on a $1.5 \mathrm{~T}$ Signa MR imaging scanner (GE Healthcare, Milwaukee, Wisconsin). A volumetric spoiled gradient recalled-echo sequence generated 124 contiguous 1.5-mm coronal sections with TE/TR, $3.3 / 14.3 \mathrm{~ms}$; flip angle, $30^{\circ}$; matrix size, $256 \times 256$; FOV, $24 \times 24 \mathrm{~cm}$; voxel dimensions, $0.938 \times 0.938 \mathrm{~mm}$.

\section{MR Imaging Segmentation}

Subcortical structures were segmented with the FMRIB Integrated Registration and Segmentation Tool (FIRST) from the FMRIB Software Library (FSL; http:// www.fmrib.ox.ac.uk/fsl). ${ }^{10}$ This process provided volumes of the left and right hippocampi, amygdala, nucleus accum-

\section{MATERIALS AND METHOD \\ Subjects}

Data were acquired from 10 adult patients with NPC (6 men, 4 women) from the Royal Melbourne Hospital, Melbourne, Australia (Table 1) between 2000 and 2010. This is a larger cohort of patients than our original voxel-based analysis ${ }^{5}$ and, given the exceptional rarity of diagnosed adult patients, constitutes the largest published sample size in a neuroimaging study in this disorder. All participants provided written informed consent, and the study was approved by the local research and ethics committee (HREC 2004.042 and 2005.198). Diagnosis was confirmed with biochemical analysis of cultured fibroblasts, by using the cholesterol esterification rate and percentage of cells staining abnormally for perinuclear cholesterol. Age at onset of neurologic symptoms and duration of symptoms were recorded, and symptoms were rated on the NPC-specific rating scale of Iturriaga et al. ${ }^{8}$ Nine patients were assessed cognitively by using the NUCOG, a cognitive screening tool that rates cognitive functioning in 5 domains: attention, memory, executive functioning, language, and visuoconstructional function. ${ }^{9}$ Patients were matched for age and sex with healthy controls ( $n=27 ; 17$ men, 10 women $)$ without a history of major medical, neurologic, or psychiatric illness. NUCOG data were not available for control participants. bens, putamen, caudate, pallidum, and thalamus (Figs 1 and 2 ). The SPGR images from both patient and control groups were transformed into Montreal Neurological Institute-152 (MNI-152) standard space via an affine transformation using $12 d f$ at $1-\mathrm{mm}$ resolution. A second registration was applied by using the MNI-152 subcortical mask to exclude voxels outside the subcortical range. Segmentation of subcortical structures was then based on shape models and voxel intensities, in which surface meshes of each subcortical structure were extracted, transformed to original MR imaging space, and then filled and boundary-corrected. Absolute volumes of subcortical structures were calculated in cubic millimeters. All segmentations were then visually checked for errors in registration and segmentation.

The ICV was determined in a semiautomated fashion by using FSL software. First, brains were skull-stripped with the Brain Extraction Tool, carefully checked for accuracy, and then aligned linearly to the MNI-152 one-millimeter T1-weighted template. The inverse of the determinant of the affine transformation matrix was multiplied by the ICV of the MNI-152 template to produce a measure of ICV for use as a scaling factor, measured in cubic centimeters.

AJNR Am J Neuroradiol 34:1334-40 Jul 2013 www.ajnr.org 1335 


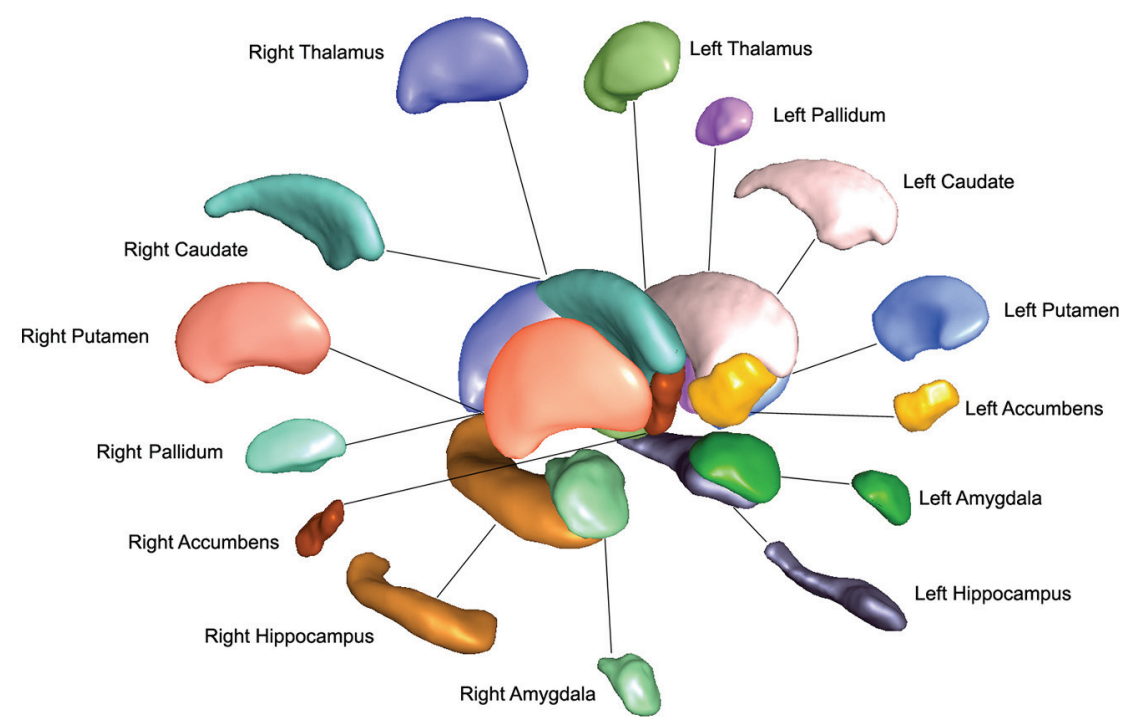

FIG 2. 3D projection of left and right deep gray matter structures produced by the FIRST algorithm.

\section{Statistical Analysis}

Comparison of the brain stem neuroimaging variables was undertaken with analysis of covariance, controlling for ICV. Effect size for each analysis of covariance was calculated by using Cohen $\eta^{2}$, with an $\eta^{2}>0.14$ constituting a large effect. ${ }^{11}$ Correlations between ocular-motor, illness, and brain stem variables were undertaken by using the Spearman correlation coefficient. Correction for multiple comparisons was undertaken by using the Holm-Bonferroni correction, which controls the family-wise error rate at a given level of $\alpha$ to minimize type I errors while performing multiple Bonferroni tests at each intersection, ${ }^{12}$ while minimizing the type II errors inherent in a simple Bonferroni correction. In this method, uncorrected $P$ values are ordered, with the smallest value compared with $0.05 / n$ (where $n=$ number of comparisons). If this value is lower, the null hypothesis is rejected, and the next smallest is compared with 0.05 / $(n-1)$; this process continues until the null hypothesis cannot be rejected and all $P$ values above this level are considered nonsignificant. For between-group comparisons, $n=14$ (7 subcortical structures in each hemisphere; for correlational analyses) and $n=18$ (3 subcortical structures in each hemisphere correlated with 3 illness variables). All analyses between total volume and clinical variables were undertaken with PASW Statistics, Version 18 (IBM, New York, New York).

\section{Vertex Analysis}

For local shape analysis on subcortical structures generated by FIRST, a modified approach to vertex analysis proposed in Patenaude et $\mathrm{al}^{10}$ was used to assess localized size and shape differences. We elected to undertake this on structures that showed significant between-group differences and on which shape analysis may allow localization of changes to regions approximating subregions or nuclei of the structures involved. ${ }^{13}$ For each structure, all subject surfaces are aligned to the mean surface from the model by using a $6-d f$ transformation. Rather than using a multi- variate test for each vertex, the new method applies a univariate general linear model to the distance along the normal by which the subject's vertex differs from the mean; smaller/larger values indicate contraction/expansion relative to the mean respectively. The distance is estimated by projecting the difference vector (mean vertex to aligned vertex) onto the corresponding surface normal (calculated from the mean surface). Multiple comparisons are controlled for by using false discovery rate correction.

\section{RESULTS}

\section{Demographic Data}

Demographic data are presented in Table 2. There was no significant difference between the control and NPC groups on measures of age $(t=0.348, P=.730)$, $\operatorname{sex}\left(\chi^{2}=0.024, P=.869\right)$, and intracranial volume $(t=0.642, P=.525)$. The mean duration of illness for the sample was $4.50 \pm 3.41$ years (range, $1-12$ years), and the mean illness scale score was $8.20 \pm 3.71$ years (range, 4-15 years; Table 1).

\section{Between-Group Analyses}

Most subcortical structures, corrected for head size, were smaller in the NPC group compared with controls (Table 2). Differences in bilateral hippocampus, thalamus, putamen, right amygdala, and caudate survived Holm-Bonferroni correction. The greatest effect size was seen in the thalamus, where $\eta^{2}$ was $>0.4$ for both left and right thalami. The hippocampus and striatum (caudate and putamen) showed effect sizes of $0.15-0.25$, with the smallest effect sizes seen in the amygdala and accumbens.

\section{Relationship between Subcortical Volumes and Illness Variables}

There was a correlation between total gray but not white matter volume with duration of illness and symptoms and a correlation with global cognitive function (Table 3). When subcortical volumes were examined, the strongest correlations were seen for the thalamus and hippocampus respectively, more so with left-sided structures. The correlations between left hippocampal volume and illness scale score and cognition survived multiple-comparison testing. No structure correlated with illness biochemical variables.

\section{Vertex Analysis}

Vertex analysis was undertaken on the hippocampus, thalamus, and caudate, shown in Fig 3. In the hippocampus, regional reductions were shown bilaterally in the laterally located CA1 region of the hippocampus, more so on the left, and in the inferiorly located left subiculum. In the thalamus, reductions were seen bilaterally in regions corresponding to the location of the anterior and lateral dorsal nuclei and the pulvinar. The caudate showed reductions in both dorsolateral and dorsomedial regions through the head, body, and tail. 
Table 2: Demographic and subcortical variables across control and NPC patient groups ${ }^{\mathrm{a}}$

\begin{tabular}{|c|c|c|c|c|c|}
\hline & NPC & Controls & Variable & $\begin{array}{c}\text { Significance } \\
(P)\end{array}$ & $\begin{array}{c}\text { Effect Size } \\
\left(\eta^{2}\right)^{\mathrm{b}}\end{array}$ \\
\hline Age (yr) & $31.50( \pm 9.62)$ & $30.24( \pm 9.78)$ & $t=0.348$ & .730 & - \\
\hline $\operatorname{Sex}(M / F)$ & $6: 4$ & $17: 10$ & $\chi^{2}=0.024$ & .869 & - \\
\hline Intracranial volume $\left(\mathrm{mm}^{3}\right)$ & $14.65( \pm 2.30) \times 10^{5}$ & $15.07( \pm 1.59) \times 10^{5}$ & $t=0.642$ & .525 & - \\
\hline Total gray matter $\left(\mathrm{mm}^{3}\right)$ & $7.84( \pm 0.69) \times 10^{5}$ & $8.44( \pm 0.39) \times 10^{5}$ & $F=5.951$ & .006 & 0.221 \\
\hline Total white matter $\left(\mathrm{mm}^{3}\right)$ & $6.36( \pm 0.35) \times 10^{5}$ & $6.76( \pm 0.35) \times 10^{5}$ & $F=5.327$ & .01 & 0.198 \\
\hline \multicolumn{6}{|l|}{ Left } \\
\hline Hippocampus (mm³) & $3407( \pm 654)$ & $4001( \pm 457)$ & $F=12.201$ & $<.001^{\mathrm{C}}$ & 0.170 \\
\hline Amygdala $\left(\mathrm{mm}^{3}\right)$ & $1262( \pm 299)$ & $1453( \pm 211)$ & $F=3.234$ & 0.052 & 0.104 \\
\hline Thalamus $\left(\mathrm{mm}^{3}\right)$ & $6297( \pm 1111)$ & $8156( \pm 781)$ & $F=18.168$ & $<.001^{\mathrm{C}}$ & 0.450 \\
\hline Caudate $\left(\mathrm{mm}^{3}\right)$ & $2966( \pm 566)$ & $3421( \pm 497)$ & $\mathrm{F}=4.192$ & .024 & 0.119 \\
\hline Putamen $\left(\mathrm{mm}^{3}\right)$ & $4229( \pm 844)$ & $5163( \pm 632)$ & $F=10.671$ & $<.001^{\mathrm{c}}$ & 0.236 \\
\hline Pallidum $\left(\mathrm{mm}^{3}\right)$ & $1526( \pm 146)$ & $1726( \pm 191)$ & $F=4.627$ & .017 & 0.192 \\
\hline Nucleus accumbens $\left(\mathrm{mm}^{3}\right)$ & $473( \pm 187)$ & $562( \pm 117)$ & $F=3.150$ & .056 & 0.039 \\
\hline \multicolumn{6}{|l|}{ Right } \\
\hline Hippocampus $\left(\mathrm{mm}^{3}\right)$ & 3343 (士 739) & $4096( \pm 451)$ & $F=17.641$ & $<.001^{\mathrm{C}}$ & 0.233 \\
\hline Amygdala $\left(\mathrm{mm}^{3}\right)$ & $1228( \pm 220)$ & $1415( \pm 245)$ & $F=14.472$ & $<.001^{\mathrm{c}}$ & 0.073 \\
\hline Thalamus $\left(\mathrm{mm}^{3}\right)$ & $6068( \pm 1140)$ & $7847( \pm 791)$ & $F=15.614$ & $<.001^{\mathrm{c}}$ & 0.423 \\
\hline Caudate $\left(\mathrm{mm}^{3}\right)$ & $3027( \pm 68)$ & $3728( \pm 558)$ & $F=6.458$ & $<.004^{c}$ & 0.227 \\
\hline Putamen $\left(\mathrm{mm}^{3}\right)$ & $4101( \pm 1188)$ & $5158( \pm 495)$ & $F=15.238$ & $<.001^{\mathrm{c}}$ & 0.249 \\
\hline Pallidum $\left(\mathrm{mm}^{3}\right)$ & $1613( \pm 272)$ & $1779( \pm 144)$ & $F=4.168$ & .024 & 0.121 \\
\hline Nucleus accumbens $\left(\mathrm{mm}^{3}\right)$ & $381( \pm 131)$ & $465( \pm 94)$ & $F=2.393$ & .107 & 0.065 \\
\hline
\end{tabular}

Note:- - indicates no statistical calculation.

a Volumes are presented as means.

${ }^{b}$ Effect sizes (Cohen d) presented for significant between-group comparisons.

c $P$ value surviving Holm-Bonferroni correction.

Table 3: Correlational matrix between volume of subcortical structures in patients with NPC and illness variables ${ }^{a}$

\begin{tabular}{|c|c|c|c|c|c|c|}
\hline & \multicolumn{2}{|c|}{ Duration of Illness (yr) } & \multicolumn{2}{|c|}{ Illness Scale Score } & \multicolumn{2}{|c|}{ NUCOG $(/ 100)$} \\
\hline & $r$ & $P$ & $r$ & $P$ & $r$ & $P$ \\
\hline \multicolumn{7}{|l|}{ Left } \\
\hline Hippocampus & -0.670 & .017 & -0.891 & $<.001^{\mathrm{a}}$ & 0.445 & $.003^{a}$ \\
\hline Thalamus & -0.623 & .027 & -0.705 & .011 & 0.767 & .008 \\
\hline Putamen & -0.226 & .265 & -0.231 & .261 & 0.185 & .317 \\
\hline \multicolumn{7}{|l|}{ Right } \\
\hline Hippocampus & -0.566 & .044 & -0.705 & .011 & 0.589 & .047 \\
\hline Thalamus & -0.597 & .034 & -0.687 & .014 & 0.779 & .008 \\
\hline Putamen & -0.332 & .182 & -0.281 & .216 & 0.190 & .312 \\
\hline
\end{tabular}

a $P$ values surviving Holm-Bonferroni correction.

\section{DISCUSSION}

These findings in gray matter nuclei are broadly in accordance with but expand the limited findings from the neuroimaging literature in NPC. The initial case series in which MR imaging was included had based analyses on visual inspection and generally reported anterior cortical and cerebellar atrophy and callosal thinning, 2,3 though hippocampal atrophy has been reported. ${ }^{3,14}$ Our previous voxel-based study described reductions in volume in the thalamus, hippocampus, striatum, and cerebellum, ${ }^{5}$ though it did not implicate all striatal nuclei. Tedeschi et $\mathrm{al}^{15}$ described proton MR spectroscopy parameters in 10 (mostly adult) patients compared with controls and showed reduced $\mathrm{NAA} /$ creatine ratios in the caudate. Battisti et al ${ }^{16}$ described significant frontal cortex, thalamic, and cerebellar hypoperfusion on FDG-PET associated with illness progression. Zaaraoui et $\mathrm{al}^{17}$ compared 2 patients individually against a group of controls by using magnetization transfer ratio and found reductions in the thalamus, putamen and globus pallidus, and cerebellum. The current study confirms the findings from these small series that volumetric changes occur in thalamic, hippocampal, and striatal re- gions in NPC and suggests that these changes progress with illness.

These findings also correlate with changes described in animal models of NPC and the limited number of human neuropathologic studies. In feline NPC models, the formation of axonal spheroids occurs in gamma-aminobutyric acid-ergic neuronal populations in the cerebellum, brain stem, hippocampus, and basal ganglia. ${ }^{18}$ In murine NPC models, intracellular storage of gangliosides occurs maximally in large pyramidal neurons, Purkinje cells in the cerebellum, and neurons in the lateral thalamus, hippocampus, and brain stem ${ }^{6,19}$; and maximal neuronal loss occurs in the thalamus and cerebellum. ${ }^{19-21}$ The earliest human neuropathologic studies showed that neuroaxonal dystrophy was maximal in the thalamus and cerebellum. ${ }^{22}$ In humans, neuropathologic studies demonstrated that noncerebellar brain regions develop NFTs in the basal ganglia, thalamus, brain stem, cerebral cortex, and hippocampus. ${ }^{7,23,24}$ The convergent animal and human data suggest that in addition to notable cerebellar Purkinje cell loss, significant changes also occur in the thalamus and hippocampus. While most visually rated MR imaging re- 


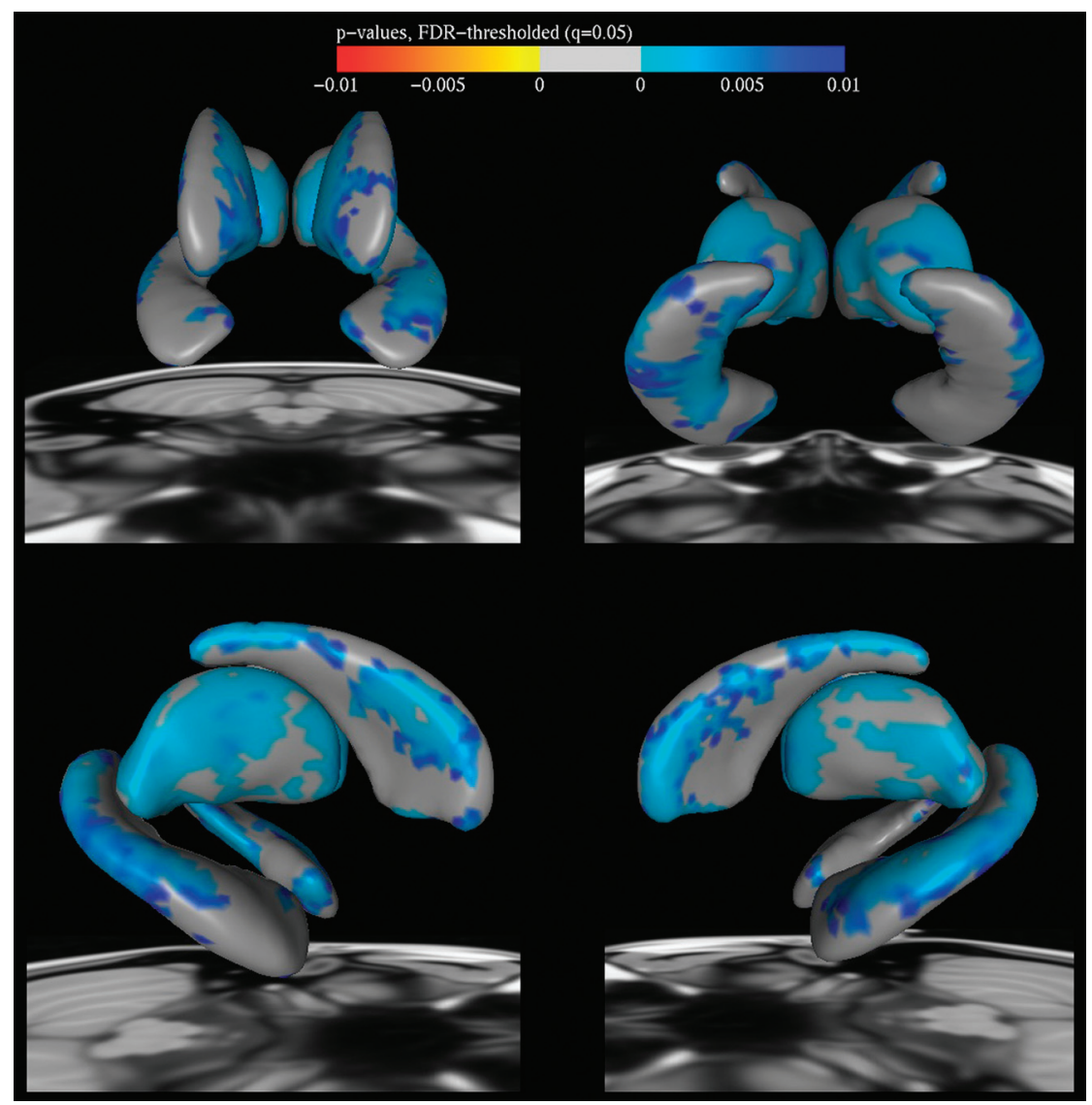

FIG 3. Vertex analysis showing regional change in the striatum, thalamus, and hippocampus. Top left, anterior view; top right, posterior view; bottom left, right lateral view; bottom right, left lateral view. Blue shows regional volumetric reduction in patients with NPC compared with controls.

ports in NPC disease focus on atrophy in surface regions such as the cerebral cortex and cerebellum, which are more obvious on T1-weighted imaging, the atrophy of deeper nuclei may be less obvious.

Neuronal loss in the hippocampus and thalamus, the subcortical regions of greatest and most significant volume loss in this study, would be expected to cause marked neuropsychological impairment in NPC. The hippocampus plays a key role in episodic and declarative memory, and because the hippocampus projects to the anterior thalamus via the fornix (to the mammillary bodies) and then via the mamillothalamic tract, pathology in the thalamus is known to cause significant impairment in both new memory encoding and executive function. Cognitive impairment is a core symptom cluster in adult NPC, in addition to movement disturbance, gaze palsy, and psychiatric illness, ${ }^{2,3}$ and is present, to some degree, in all adult patients at diagnosis and progresses with time. ${ }^{2}$ Significant memory and executive impairment have been described in a number of adult patients in case reports ${ }^{2,3,14,25}$; however, few studies have systematically examined cognitive function in adult patients with NPC. Klarner et $\mathrm{al}^{26}$ demonstrated that verbal memory impairment was present in most adult patients with moderate progression, whereas executive impairment occurred early. Hinton et $\mathrm{al}^{27}$ also showed that verbal memory impairment was present in 13/14 adolescent and adult patients, and all patients had demonstrably impaired exec- utive function. These findings suggest that the memory impairment in adult NPC is related to the primacy of pathology affecting the hippocampus in particular and the thalamus.

Results of the vertex analyses for the hippocampus showed significant reductions in the CAl region, a zone vulnerable to metabolic stress and where NFT formation is regionally concentrated in human patients with NPC. ${ }^{23}$ The CA1 region is crucial for autobiographic memory retrieval and spatial learning. ${ }^{28}$ The subiculum, where particular reductions were seen on the left (and where NFTs are also found but are less numerous than in $\mathrm{CA}^{23}$ ), is principally concerned with spatial navigation and mnemonic processing. ${ }^{29}$ These findings consolidate the assertion that memory impairment in adult NPC is driven by hippocampal pathology.

In addition, the regional reductions seen in the thalamus implicated the anterior and lateral dorsal nuclei and the pulvinar. The anterior nucleus receives input from the hippocampus, cingulate, and hypothalamus, projecting back to these regions, and is involved in recognition memory; pathology in this nucleus results in varying levels of verbal and spatial memory impairment. ${ }^{30}$ The lateral dorsal nucleus has similar connections and appears to act in concert with it in spatial learning and memory. ${ }^{31}$ The pulvinar plays a key role in stimulus-driven visual attention and has reciprocal connections throughout the cortex, particularly the frontal and visual cortices. ${ }^{32}$ It may also integrate cortical control of voluntary eye movements from the frontal cortex with reflexive movements that originate in the superior colliculus, ${ }^{33}$ and pathology may thus contribute to the deficits seen in self-generated saccades and antisaccade performance in adult NPC. ${ }^{33}$ It is possible that the thalamic volume loss is primary, related to both altered neuronal ultrastructure and NFT formation in this region, ${ }^{23}$ but given the close functional relationship with the hippocampus, there may be a contribution of trans-synaptic degeneration secondary to deafferentation, which is known to affect the anterior thalamic nuclei in hippocampal sclerosis. ${ }^{34}$

The volumetric reductions in the basal ganglia, though not significant when corrected for multiple comparisons, are consistent with the motor findings in adult NPC. Whereas ataxia follows early loss of cerebellar Purkinje neurons, dystonia is also common, with Parkinsonism and chorea occurring in a small group of patients. ${ }^{2}$ Only a small group of studies has specifically examined dystonia in NPC. Floyd et $\mathrm{al}^{35}$ examined 15 adult patients with NPC by using accelerometry and surface electromyography; 13/15 showed physiologic evidence of action tremor; 6/15, of dystonia; and 2/15, of myoclonus. In 14 adolescent/adult patients 
and 14 matched controls, spiral analysis of upper limb kinematics found tremor in most patients but also showed abnormal pressure-time relationships consistent with focal dystonia. ${ }^{36}$ Dystonia occurs in concert with the pathology of the basal ganglia, the putamen in particular. This study showed the greatest volumetric loss in the putamen, followed by caudate and pallidal volumes. The basal ganglia is a known site of neurofibrillary tangle formation in human patients with $\mathrm{NPC}^{7,23}$ and of marked neuroaxonal dystrophy in the feline NPC model. ${ }^{37}$

Cerebellar dysfunction may also play a role in contributing to dystonia, via cerebellar-basal ganglia connections through the thalamus, red nucleus, and zona incerta ${ }^{38}$; the interaction of both cerebellar and basal ganglia pathology may thus underpin the high rate of dystonia in adult patients with NPC. The vertex analysis of the caudate showed that dorsolateral regions were particularly affected; this region of the caudate is a central node in the dorsolateral prefrontal cortical loop, which reciprocally connects this region of the caudate to the dorsolateral prefrontal cortex. This circuit subserves executive function, such as problem-solving, self-direction and judgment, and shifting behavioral set. The executive impairment frequently described in the illness ${ }^{26,27}$ may thus also be increased by dysfunction in this frontostriatal circuitry. The caudate also plays a role in inhibiting saccade neurons in the superior colliculus ${ }^{39}$; damage to this pathway leads to errors on the antisaccade task, a task that patients with NPC perform poorly if at all. ${ }^{40}$

The nucleus accumbens showed modest nonsignificant volumetric reductions in our study. The accumbens is thought to function as the interface between limbic and motor systems and to play a significant role in goal-directed behavior, the reward system, and addiction. ${ }^{41}$ Abnormalities in the accumbens have also been implicated in schizophrenia, ${ }^{42}$ and if function of the accumbens is impaired in NPC, it may be related to the high prevalence of schizophrenia-like psychosis in the disorder. ${ }^{2,3}$ The only study to examine the accumbens in NPC, however, found no reductions in number but did find abnormal morphology in accumbal cholinergic neurons. ${ }^{19}$

Finally, modest reductions were seen in amygdala size in our adult NPC cohort. The amygdala is known to play a role in emotional regulation and social cognition; bilateral amygdala lesions are known to result in the lack of awareness of threat and in social disinhibition. ${ }^{43}$ Social disinhibition and a lack of interpersonal "distance" have frequently been described in adult patients with NPC. ${ }^{3,14}$ Neurofibrillary tangles and distended neurons have been described in the amygdala in human patients with $\mathrm{NPC}^{7,23}$; thus, it may be that disruptions to the normal amygdalar function of modulating social interactions may underpin the phenomenon of impaired social inhibition in adult patients with NPC.

An intriguing interpretation of our findings is that the neuropathology intrinsic to NPC preferentially affects brain regions that serve as large "connection hubs" (ie, regions that are most highly anatomically connected to other brain regions, such as the hippocampus, striatum, and thalamus). ${ }^{44}$ As described, these regions are in areas where there is significant overlap between regional toxic ganglioside excess and NFT accumulation. It is also possible that given the widespread white matter changes in NPC, ${ }^{4,5}$ volumetric loss in these regions is reflective of pathology in their attenuated anatomic interconnections. If these hub regions are preferentially affected, then this potential suggests that select neocortical regions that are similarly attenuated, such as entorhinal and retrosplenial cortices and frontal regions such as orbitofrontal and dorsolateral prefrontal zones, ${ }^{44-46}$ may also show regional vulnerability. We have extended our initial exploratory VBM approach with a specific examination of subcortical structures, and the role of neocortical regions in NPC pathology warrants testing by using specific cortically based analysis methods.

The key limitation of this study is its sample size, which, despite the rarity of adult NPC, remains modest. This size limits the generalizability of our findings to all patients, particularly pediatric patients. However, this limitation is mitigated by the broad age range of our patient group, from early adulthood to middle age, which affords significant variance in our sample as seen in Table 1. Sample size also limits our statistical approach, preventing more sophisticated analyses such as multivariate regression. Given the high number of between-group comparisons and correlations for this sample size, we have attempted to control for multiple comparisons by using a method that aims to balance type I and II errors. In addition, volumetric analysis is limited in its capacity to inform us about brain function; only when significant neuronal loss has already occurred would volumetric changes follow. Thus our method is relatively insensitive to early neuronal changes that cause functional but not gross anatomic disruption to the deep gray matter regions involved in this study. Other MR imaging-based measures that probe function and microstructure, such as MR spectroscopy or magnetization transfer ratio, may be more sensitive to early changes but can be limited by voxel size and placement.

\section{CONCLUSIONS}

We have demonstrated that patients with adult NPC show key volume reduction in a number of subcortical regions compared with healthy individuals, occurring in sites where neuropathologic abnormalities have been shown to occur. These alterations may underpin some of the key motor, cognitive, and emotional features of adult NPC. Larger cohorts and longitudinal studies will allow a clearer understanding of how these structural changes correlate to specific clinical features and how the timing of changes in brain structure and function relate to the onset of symptoms of this disease.

\section{ACKNOWLEDGMENTS}

The authors wish to acknowledge the generous assistance of patients and their families.

Disclosures: Mark Walterfang-UNRELATED: Consultancy: Actelion Pharmaceuticals, Comments: International advisory board, Payment for Lectures (including service on Speakers Bureaus): Actelion, Comments: payment of honorarium for speaking at International NPC forum, Royalties: Australian Council for Educational Research, Comments: payment of royalties for the NUCOG, a pen-and-paper cognitive screening tool. Brian Patenaude-OTHER RELATIONSHIPS: I work with Oxford University (the FSL group) in development of the subcortical segmentation tool. No compensation for these activities is received. Larry A. Abel—UNRELATED: Consultancy: Actelion, ${ }^{\star}$ Comments: consulting fee for Miglustat clinical trials 
(2004-2005), Payment for Lectures (including service on Speakers Bureaus): Actelion, ${ }^{*}$ Comments: honoraria for presentations at 2 Actelion-sponsored meetings on NPC in Athens, Greece, March 2012 and Prague, Czech Republic, June 2012. Hans Klunemann—UNRELATED: Board Membership: Actelion, Consultancy: Actelion, Grants/Grants Pending: Actelion;* Payment for Lectures (including service on Speakers Bureaus): Actelion, Comments: lectures about dementia for Pfizer, Lilly, GlaxoSmithKline, Actelion, Lundbeck, Merz Pharmaceuticals, Payment for Development of Educational Presentations: Actelion, Travel/Accommodations/Meeting Expenses Unrelated to Activities Listed: Actelion. Michael Fahey-UNRELATED: Board Membership, Consultancy: Actelion, Comments: honoraria for advisory board membership and consultancy. Patricia Desmond-UNRELATED: Grants/ Grants Pending: National Health and Medical Research Council of Australia, ${ }^{*}$ Comments: awarded to an affiliated institution of Melbourne University for a different research project. Dennis Velakoulis_UNRELATED: Royalties: Royalties received for the cognitive screening tool NUCOG. *Money paid to the institution.

\section{REFERENCES}

1. Vanier M, Millat G. Niemann-Pick disease type C. Clin Genet 2003;64:269-81

2. Sévin M, Lesca G, Baumann N, et al. The adult form of NiemannPick disease type C. Brain 2007;130:120-33

3. Walterfang M, Fietz M, Fahey M, et al. The neuropsychiatry of Niemann-Pick type $\mathrm{C}$ disease in adulthood. J Neuropsychiatry Clin Neurosci 2006;18:158-70

4. Walterfang M, Fahey M, Abel L, et al. Size and shape of the corpus callosum in adult Niemann-Pick type $C$ reflects state and trait illness variables. AJNR Am J Neuroradiol 2011;32:1340-46

5. Walterfang M, Fahey M, Desmond $\mathrm{P}$, et al. White and gray matter alterations in adults with Niemann-Pick disease type C: a crosssectional study. Neurology 2010;75:49-56

6. Zervas M, Dobrenis K, Walkley S. Neurons in Niemann-Pick type C accumulate gangliosides as well as unesterified cholesterol and undergo dendritic and axonal alterations. J Neuropathol Exp Neurol 2001;60:49-64

7. Suzuki K, Parker C, Pentchev P, et al. Neurofibrillary tangles in Niemann-Pick disease type C. Acta Neuropathol 1995;89:227-38

8. Iturriaga C, Pineda M, Fernandez-Valero E, et al. Niemann-Pick C disease in Spain: clinical spectrum and development of a disability scale. J Neurol Sci 2006;249:1-6

9. Walterfang M, Siu R, Velakoulis D. The NUCOG: validity and reliability of a brief cognitive screening tool in neuropsychiatric patients. Aust N Z J Psychiatry 2006;40:995-1002

10. Patenaude B, Smith S, Kennedy D, et al. A Bayesian model of shape and appearance for subcortical brain segmentation. Neuroimage 2011;56:907-22

11. Cohen J. Statistical Power Analysis for the Behavior Sciences. New York: Routledge; 1988

12. Holm S. A simple sequentially rejective multiple test procedure. Scand J Statistics 1979;6:65-70

13. Patenaude B, Smith S, Kennedy D, et al. Bayesian Shape and Appearance Models: FMRIB Technical Report. Oxford, UK: Oxford University; 2007

14. Sullivan D, Walterfang M, Velakoulis D. Bipolar disorder and Niemann-Pick disease type C. Am J Psychiatry 2005;162:1021-22

15. Tedeschi G, Bonavita S, Barton N, et al. Proton magnetic resonance spectroscopic imaging in the clinical evaluation of patients with Niemann-Pick type C disease. J Neurol Neurosurg Psychiatry 1998;65:72-79

16. Battisti C, Tarugi P, Dotti MT, et al. Adult onset Niemann-Pick type $\mathrm{C}$ disease: a clinical, neuroimaging and molecular genetic study. Mov Disord 2003;18:1405-09

17. Zaaraoui $W$, Crespy $L$, Rico A, et al. In vivo quantification of brain injury in adult Niemann-Pick Disease Type C. Mol Genet Metab 2011;103:138-41

18. Walkley S, Baker H, Rattazzi M, et al. Neuroaxonal dystrophy in neuronal storage disorders: evidence for major GABAergic neuron involvement. J Neurol Sci 1991;104:1-8

19. German D, Quintero E, Liang C, et al. Selective neurodegeneration, without neurofibrillary tangles, in a mouse model of Niemann-Pick C disease. J Comp Neurol 2001;433:415-25

20. Yamada A, Saji M, Ukita Y, et al. Progressive neuronal loss in the ventral posterior lateral and medial nuclei of thalamus in Niemann Pick disease type C mouse brain. Brain Dev 2001;5:288-97

21. Lopez ME, Klein AD, Dimbil UJ, et al. Anatomically defined neuron-based rescue of neurodegenerative Niemann-Pick type C disorder. I Neurosci 2011;31:4367-78

22. Elleder M, Jirasek A. Neuropathology of various types of NiemannPick disease. Acta Neuropathol Suppl 1981;7:201-03

23. Love S, Bridges L, Case C. Neurofibrillary tangles in Niemann-Pick disease type C. Brain 1995;118:119-29

24. Suzuki K, Parker C, Pentchev P. Niemann-Pick disease type C: neuropathology revisited. Developmental Brain Dysfunction 1997;10: 306-20

25. Klünemann HH, Elleder M, Kaminski WE, et al. Frontal lobe atrophy due to a mutation in the cholesterol binding protein HE1/ NPC2. Ann Neurol 2002;52:743-49

26. Klarner B, Klünemann HH, Lürding R, et al. Neuropsychological profile of adult patients with Niemann-Pick C1 (NPC1) mutations. J Inherit Metab Dis 2007;30:60-67

27. Hinton V, Vecchio D, Prady H, et al. The cognitive phenotype of type $\mathrm{C}$ disease: neuropsychological characteristics of patients at baseline in a clinical trial with oral Miglustat. In: Proceedings of the Annual Meeting of the American Society of Human Genetics, Salt Lake City, Utah. October 25-29, 2005

28. Bartsch T, Dohring J, Rohr A, et al. CA1 neurons in the human hippocampus are critical for autobiographical memory, mental time travel, and autonoetic consciousness. Proc Natl Acad Sci U S A 2011;108:17562-67

29. O'Mara S. Controlling hippocampal output: the central role of subiculum in hippocampal information processing. Behav Brain Res 2006;174:304-12

30. Nishio Y, Hashimoto M, Ishii K, et al. Neuroanatomy of a neurobehavioral disturbance in the left anterior thalamic infarction. J Neurol Neurosurg Psychiatry 2011;82:1195-200

31. van Groen T, Kadish I, Wyss JM. The role of the laterodorsal nucleus of the thalamus in spatial learning and memory in the rat. Behav Brain Res 2002;136:329-37

32. Romanski LM, Giguere M, Bates JF, et al. Topographic organization of medial pulvinar connections with the prefrontal cortex in the rhesus monkey. J Comp Neurol 1997;379:313-32

33. Van der Stigchel S, Arend I, van Koningsbruggen MG, et al. Oculomotor integration in patients with a pulvinar lesion. Neuropsychologia 2010;48:3497-504

34. Bonilha L, Rorden C, Castellano G, et al. Voxel-based morphometry of the thalamus in patients with refractory medial temporal lobe epilepsy. Neuroimage 2005;25:1016-21

35. Floyd AG, Yu QP, Piboolnurak P, et al. Kinematic analysis of motor dysfunction in Niemann-Pick type C. Clin Neurophysiol 2007;118 1010-18

36. Hsu AW, Piboolnurak PA, Floyd AG, et al. Spiral analysis in Niemann-Pick disease type C. Mov Disord 2009;24:1984-90

37. March PA, Thrall MA, Brown DE, et al. GABAergic neuroaxonal dystrophy and other cytopathological alterations in feline NiemannPick disease type C. Acta Neuropathol 1997;94:164-72

38. Neychev VK, Fan X, Mitev VI, et al. The basal ganglia and cerebellum interact in the expression of dystonic movement. Brain 2008;131 2499-509

39. Ford KA, Everling S. Neural activity in primate caudate nucleus associated with pro- and antisaccades. J Neurophysiol 2009;102: 2334-41

40. Abel L, Walterfang M, Fietz M, et al. Saccades in adult Niemann-Pick disease type $\mathrm{C}$ reflect frontal, brainstem, and biochemical deficits. Neurology 2009;72:1083-86

41. Humphries MD, Prescott TJ. The ventral basal ganglia, a selection mechanism at the crossroads of space, strategy, and reward. Prog Neurobiol 2010;90:385-417

42. Pakkenberg B. Pronounced reduction of total neuron number in mediodorsal thalamic nucleus and nucleus accumbens in schizophrenics. Arch Gen Psychiatry 1990;47:1023-28

43. Amaral DG. The primate amygdala and the neurobiology of socia behavior: implications for understanding social anxiety. Biol Psychiatry 2002;51:11-17

44. Cole MW, Pathak S, Schneider W. Identifying the brain's most globally connected regions. Neuroimage 2010;49:3132-48

45. Bassett DS, Bullmore E, Verchinski BA, et al. Hierarchical organization of human cortical networks in health and schizophrenia. J Neurosci 2008;28:9239-48

46. Becerra L, Pendse G, Chang PC, et al. Robust reproducible resting state networks in the awake rodent brain. PLoS One 2011;6: e25701 